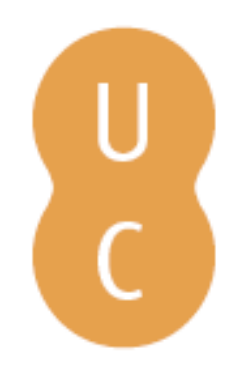

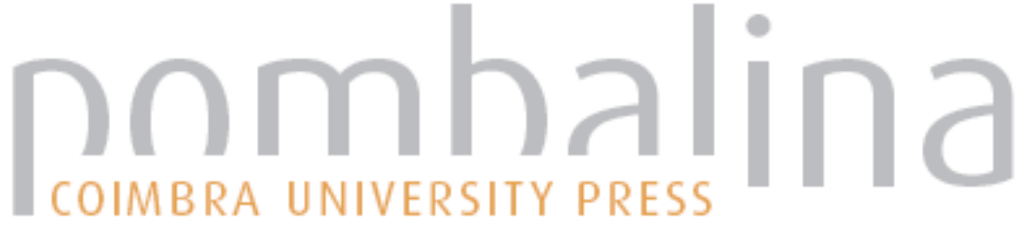

\section{Urbanismo escolar: contributos para a definição e aplicação do conceito}

Autor(es): $\quad$ Pereira, Margarida; Pisco, Paulo

Publicado por: Imprensa da Universidade de Coimbra

URL

persistente:

URI:http://hdl.handle.net/10316.2/30831

DOI:

DOI:http://dx.doi.org/10.14195/978-989-26-0244-8_47

Accessed : $\quad$ 26-Apr-2023 04:55:28

A navegação consulta e descarregamento dos títulos inseridos nas Bibliotecas Digitais UC Digitalis, UC Pombalina e UC Impactum, pressupõem a aceitação plena e sem reservas dos Termos e Condições de Uso destas Bibliotecas Digitais, disponíveis em https://digitalis.uc.pt/pt-pt/termos.

Conforme exposto nos referidos Termos e Condições de Uso, o descarregamento de títulos de acesso restrito requer uma licença válida de autorização devendo o utilizador aceder ao(s) documento(s) a partir de um endereço de IP da instituição detentora da supramencionada licença.

Ao utilizador é apenas permitido o descarregamento para uso pessoal, pelo que o emprego do(s) título(s) descarregado(s) para outro fim, designadamente comercial, carece de autorização do respetivo autor ou editor da obra.

Na medida em que todas as obras da UC Digitalis se encontram protegidas pelo Código do Direito de Autor e Direitos Conexos e demais legislação aplicável, toda a cópia, parcial ou total, deste documento, nos casos em que é legalmente admitida, deverá conter ou fazer-se acompanhar por este aviso. 


\section{TRUNFOS DE UMA}

\section{EOGRAFIA ACIVA}

\section{DESENVOLVIMENTO LOCAL,}

AMBIENTE,

ORDENAMENTO

E TECNOLOGIA

Norberto Santos

Lúcio Cunha

COORDENAÇÃO 


\author{
Margarida Pereira ${ }^{1}$, Paulo Pisco ${ }^{2}$ \\ ${ }^{1}$ e-Geo: Centro de Estudos de Geografia e Planeamento Regional, FCSH/ UNL \\ ${ }^{2}$ CESUR - Centro de Estudos de Sistemas Urbanos e Regionais, IST/UTL
}

\title{
URBANISMO ESCOLAR: CONTRIBUTOS PARA A DEFINIÇÃO E APLICAÇÃO DO CONCEITO
}

\section{INTRODUÇÃO}

Os equipamentos colectivos, e em particular a escola, assumiram uma posição de destaque nos modelos urbanísticos propostos desde o final do século XIX. O processo de desenvolvimento urbano no último século e as disfunçóes associadas justificam os princípios defendidos para a sustentabilidade urbana. Preocupaçóes como a equidade, o combate à pobreza, à marginalização e à insegurança, apontam para a retoma (com redefinição) do conceito de proximidade e a revalorização da comunidade e, nesta abordagem, a escola pode recuperar o papel que foi perdendo.

$\mathrm{O}$ artigo apresenta as razóes para uma nova relação entre a cidade e a escola, e justifica a introdução do Urbanismo Escolar como uma estratégia territorial para a capacitação das pessoas e dos territórios, articulando escalas e integrando instrumentos e políticas públicas.

\section{RELAÇÃO CIDADE \& ESCOLA: JUSTIFICAÇÃO PARA A MUDANÇA}

Em Portugal, as últimas décadas são marcadas pelo acelerado processo de urbanização, pela litoralização do povoamento e da economia e pela alteraçáo estrutural da cidade. A procura escolar acompanhou as tendências demográficas e a redistribuição espacial da população, bem como as mudanças no sistema educativo, em particular provocadas pelos progressivos alargamentos da escolaridade obrigatória. A rede escolar contribuiu pouco para a estruturação urbana e o ordenamento do território, andando, por regra, a reboque da "pressáo» da procura. A localizaçáo dos equipamentos foi pouco cuidada quer na selecção dos lugares e dos terrenos (quase sempre nos disponíveis e não nos adequados) quer na sua articulação e inserção com o tecido urbano (muitas vezes surgindo como apêndice ou "quisto" na área de acolhimento) reflectindo-se como metáfora urbana da desadequação entre o ensino, a sociedade e o território. A expansão acelerada do sistema criou disfunçôes, só corrigidas com o abrandamento da procura.

A par da reorganizaçáo dos assentamentos humanos, as desigualdades sociais e territoriais têm-se ampliado e o declínio económico (e demográfico) de alguns territórios também aumentou, fruto da sua incapacidade competitiva num ambiente de crescente internacionalização da economia. Nas sociedades desenvolvidas procura-se «a igualdade de 
oportunidades e não a igualdade de rendimentos» (OCDE 2008, p. 4) e para o conseguir os serviços públicos, em particular os de proximidade, podem desempenhar um central para atingir esse objectivo (Pereira \& Pisco 2010).

A relação entre o nível de capital humano e a pobreza estrutural é muito relevante. $\mathrm{O}$ acesso à escola não alterou esta fatalidade: há uma significativa transmissão inter-geracional do grau de educação, o que contribui para a sucessão da pobreza de pais para filhos (Alves 2009; Carneiro 2008). Este facto coloca desafios na articulação da educação com o território para contrariar «espirais de declínio» que alimentam a pobreza estrutural.

Numa sociedade cada vez mais fragmentada, a diferenciação é aceite como referencial de afirmaçáo individual. Os produtos e serviços apostam aí o seu factor competitivo, procurando soluçóes personalizadas. Com a sua crescente autonomia, também a escola se aproxima do «local» para dar respostas mais adequadas aos interesses da comunidade. O poder de escolher alarga-se aos serviços públicos, porque "capacidade de acesso conjuga-se com diferenciaçáo desejada e não igualização» (Marques 2004, p.347). Muitos passam a considerar a escolha da escola não só um direito das famílias mas um dever do Estado. Esta possibilidade introduz uma lógica de mercado nos serviços públicos, mais virados para responder ao cidadão/cliente e, nessa lógica é indispensável a prestação de contas e a avaliação.

Pelo que foi dito, a eficácia e eficiência no sistema de ensino passam, não só por um investimento na melhoria dos recursos (o que tem ocorrido em Portugal) mas sobretudo por uma maior coesão territorial e equidade social (Pereira \& Pisco 2010). Porém, estas dimensóes têm merecido tratamento desigual. Novas respostas são necessárias na Educação e no Urbanismo para que a sua relação potencie a resolução de problemas e o alcance das metas que a sociedade pretende atingir. O Urbanismo Escolar pode dar um contributo.

\section{URBANISMO ESCOLAR: O QUE PODERÁ SER}

O desempenho escolar depende de factores exógenos à aprendizagem.

A casa é o espaço (habitação) da comunidade nuclear (família). Na habitação três aspectos podem afectar o rendimento escolar: a sua qualidade; o número de pessoas por fogo; a sua localização (Lubell \& Brennan 2007). A família é decisiva nos resultados escolares, como o confirma o "estatuto socioeconómico» ${ }^{1}$, calculado a partir de indicadores familiares (Perry 2007).

O «efeito de composição» ou de contexto, é o resultado do conjunto dos discentes de uma escola e está associado às qualidades impotáveis aos alunos, suas famílias e ao «efeito dos pares», considerado determinante nos resultados escolares (Lima 2008).

$\mathrm{O}$ «efeito escola» traduz a influência da escola como organização. Embora revalorizado nos últimos anos através das "escolas eficazes», mesmo os seus defensores aceitam que apenas explica 5 a 15 por cento do desempenho escolar (Lima 2008, p. 249). Pode ser induzido pelos recursos humanos e pelos recursos físicos: nos primeiros sobressai a qualidade (da liderança, dos professores, funcionários) e o clima de escola; nos segundos: a dimensão da escola; a dimensão da turma/classe; a idade, qualidade e estética do edifício; a qualidade do ar, ventilação e conforto térmico no edifício (Schneider 2002). O que determina a

\footnotetext{
${ }^{1}$ Este estatuto, no estudo de Perry (2007), realizado a partir do PISA, tem como medidas: profissão dos pais; o nível de educação dos pais; os bens culturais relacionados com a cultura clássica.
} 
relação entre a casa e a escola é a distância entre elas e as suas qualidades. A primeira coloca problemas de mobilidade, acesso e serviço; a segunda acrescenta a satisfação das necessidades/expectativas da comunidade educativa. Com o reforço da mobilidade e os modos de vida urbanos contemporâneos, a proximidade já não parece tão relevante, mas para a maioria dos alunos continua a ser determinante na escolha da escola. As propostas de sustentabilidade urbana e comunitária reforçam esse elo. $\mathrm{O}$ modo de transporte (a pé, automóvel ou transporte público) e o serviço (horários, actividades extra curriculares, cantina, etc.) são o que releva para a vida dos alunos, famílias e recursos humanos envolvidos. A dimensáo da escola tem impacte urbanístico e escolar: uma unidade maior implica mais alunos, mais professores e funcionários, maior terreno, maior área de irradiação. Também pode significar mais serviços, mais facilidade de gestáo e ganhos em economias de escala.

$\mathrm{O}$ "efeito vizinhança» traduz o modo como uma comunidade num território urbano (bairro) pode influenciar os seus moradores e é caracterizado por seis dimensóes: qualidade dos serviços públicos de proximidade; socializaçáo pelos adultos; influência dos pares; rede social; exposição ao crime e à violência; distância física e isolamento (Ellen \& Turner 1997).

$\mathrm{O}$ «efeito metrópole», associado à segmentação social expressa no território, gera mais bolsas de pobreza e desigualdade e tem com os sistemas públicos de educação uma relação de reprodução da pobreza, em vez de a eliminar. Nos territórios em perda populacional, o isolamento e a pobreza provocam dinâmicas negativas no desempenho escolar, em particular no abandono precoce. Estas tendências criam assimetrias na rede: entre a oferta e a procura e entre níveis de desempenho escolar. As dinâmicas positivas do território polarizam e acentuam os resultados das suas escolas e o inverso também é verdadeiro (Pisco 2005; Pisco 2009). A localização da escola e da habitação e o seu contexto envolvente aparecem assim como determinantes na eficiência e eficácia da escola. Em Portugal, só alguns estudos recentes evidenciaram a relação do território com a escola e o seu desempenho (Pisco 2005; Pisco 2009), mas muitos estudos internacionais apontam à concentração territorial de pobreza a responsabilidade do insucesso das escolas que as servem (Mackoy \& Vicent 2008; Ribeiro 2008; Kaztman \& Rematoso 2005).

Em Portugal criaram-se os agrupamentos escolares ${ }^{2}$ como uma rede de equipamentos que serve um "território educativo» assegurando a escolaridade obrigatória em funcionamento vertical integrado (MEa, 2000). Esta solução permite partilhar recursos, saberes, gestão e criar um projecto educativo comum para um determinado contexto territorial. Mas as Cartas Educativas supra-municipais são quase inexistentes, embora sejam pertinentes em territórios fortemente urbanizadas e em territórios de baixa densidade, onde as complementaridades são indispensáveis: para gerir a quantidade e qualidade de oferta em relação à procura, nos primeiros; para colmatar a falta de massa crítica, nos segundos.

Conceito. O «Urbanismo Escolar» é inexistente na literatura internacional. Mas o planeamento escolar está consagrado nos países que tornaram acessível o ensino ao maior número. Esta forma de provisionar escola para todos assume diversas nomenclaturas e abordagens ao longo do espaço e do tempo ${ }^{3}$. Em Portugal a Carta Educativa $\left(2003^{4}\right)$ suce-

\footnotetext{
${ }^{2}$ DL 115/98 de 4 de Maio «Regime de Autonomia e Gestão dos estabelecimentos de educação pré-escolar e dos ensinos básico e secundário.

${ }^{3}$ School Planning, School Plant Planning, School Site, School Allocation Plans (USA), School Mapping (ONU), School Organisation Plan (UK), Carte Scolaire (França), School Catchments Areas, School Zoning, Carta Educativa (Portugal).
} 
deu à Carta Escolar $\left(1998^{5}\right)$, que inovou em relação aos Critérios de Programação dos equipamentos de ensino do CEP (1978) e mais tarde da DGOTDU (2001).

O termo Urbanismo Escolar foi utilizado por Gaspar (2000; 2006), tendo enumerado o que deveria nortear este "novo urbanismo». A diferença face aos conceitos de planeamento escolar prende-se com a ambiçáo de este ser mais do que um instrumento sectorial, elevando-o a estratégia territorial onde "O Ordenamento do Território, o Planeamento Urbanistico e a arquitectura urbana podem constituir oportunidades educativas e, ao mesmo tempo, situaçóes de intensa participaçáo civica, contribuindo para o renascimento da polis, num processo de baixo para cima» (Gaspar 2000, p. 264). Este novo urbanismo estuda e operacionaliza a relação entre o sistema educativo e o sistema urbano e as implicaçóes quer na melhoria dos seus desempenhos (eficiência e eficácia), quer na construçáo de uma sociedade mais desenvolvida, coesa e equitativa.

$\mathrm{Na}$ economia do conhecimento, a aprendizagem é central no quotidiano do homem. Mas essa centralidade é dinâmica, evolui ao longo da vida e das geografias percorridas. Esta realidade está a mudar o Urbanismo e a Educaçáo, assim como as relaçóes da Cidade com a Escola. Com os tempos, os espaços e as funçóes que aí ocorrem a alterarem-se, o estudo tem de ser dinâmico e holístico, incorporando a complexidade inerente a esta realidade. E os instrumentos que podem tornar operativo o Urbanismo Escolar teráo de conter capacidade de flexibilidade e de adaptação para que a transformação no território e na escola seja positiva para os objectivos a que se propóe.

Objecto. O Urbanismo Escolar está centrado na relação entre o urbanismo e a educação, materializada no território através da cidade e da escola. Entendendo o Urbanismo como a arte, a ciência e a técnica para melhorar o território para as comunidades que alberga e a Educação como a arte, a ciência e a técnica para elevar o ser humano nos seus aspectos intelectual, moral e físico, bem como na sua inserção na sociedade, as duas disciplinas são direccionadas para a qualificação: do espaço ou da pessoa na sua relaçáo com o outro enquanto ser social e comunitário. Sendo a Cidade o lugar onde os homens vivem e a Escola o lugar onde estes aprendem, ambas e a sua relaçáo são o nosso objecto de estudo.

Objectivos. O Urbanismo e a Educação visam, enquanto políticas públicas, a promoção do desenvolvimento, da coesão e da equidade. Estes objectivos, centrais do Urbanismo Escolar, são assim entendidos: o Desenvolvimento enquanto «(...) processo de aumento das escolhas das pessoas, que lhes permitam levar uma vida longa e saudável, adquirir conhecimento, ter acesso aos recursos necessários para ter um nivel de vida digno enquanto os preservam para as geraçóes futuras, proteger a segurança pessoal e alcançar a igualdade para todas as mulheres $e$ homens.» (Amaro 2006, p.452); Coesão, enquanto processo que privilegia o território como factor de integração de comportamentos, centrando-se na capacidade deste (país, região, cidade) construir uma economia competitiva e uma sociedade coesa; a Equidade enquanto processo que procura a Igualdade de Oportunidades, proporcionada a todos de forma justa mas não igualitária.

Metodologia e Instrumentos. O Urbanismo Escolar deve ser um "processo de baixo para cima» (Gaspar, 2000, p. 264) na forma de equacionar os problemas e as soluçóes. Esta

\footnotetext{
${ }^{4}$ Através do DL n. ${ }^{o}$ 7/2003 de 15 de Janeiro, apesar do Manual para a Elaboração da Carta Educativa (MEb, 2000) e os Critérios de Reordenamento da Rede Educativa (MEa, 2000) serem anteriores.

${ }^{5}$ Lei n. ${ }^{\circ} 159 / 99$ de 14 de Setembro.
} 
abordagem reconhece a importância do urbanismo e da educação na melhoria dos territórios e dos seus habitantes e que um sem o outro não atingem os objectivos a que se propóem.

A relação do urbano com a educação resulta da interacção entre território e comunidade. A criação de indicadores escolares e urbanos permite relacionar e avaliar a qualidade dessa relação e a sua monitorização.

À margem das especificidades locais, é possível perceber que a eficiência e eficácia de cada escola/território dependem do contexto associado. As suas trajectórias, ascendentes ou descendentes, condicionam a sua atractividade. Os sectores sociais mais dinâmicos tendem a abandonar uns e a privilegiar outros, potenciando ou quebrando os desempenhos escolar e urbano.

Em Portugal o quadro legal (relativo ao ordenamento do território e urbanismo e à educação) pretende assegurar a equidade dos dois sistemas, mas os resultados estão longe do desejável. A Carta Educativa deu passos significativos como instrumento integrador da política da rede escolar com a política de planeamento do território, através da criação e operacionalizaçáo de conceitos como "território educativo» e "agrupamento de escola», para garantir aos alunos de uma comunidade o percurso da escolaridade obrigatória no mesmo projecto educativo. Mas tem privilegiado o acerto entre a oferta e a procura no contexto concelhio, ignorando problemas colocados a outras escalas e dimensóes: ao não contemplar a escala do desenho urbano ou a escala supra-municipal, e ao procurar responder às solicitaçóes quantitativas, em vez das qualitativas (da eficiência dos recursos e suas interacçóes), omite parte das questóes a resolver.

O desenvolvimento e a coesão territorial são objectivos onde a equidade no acesso, no tratamento e desempenho aos recursos territoriais é a medida do seu sucesso. Para se atingirem estes objectivos, a metodologia deverá identificar os factores críticos de cada território e contrariar, através da intervenção pública, as suas tendências negativas. A exclusão, associada à pobreza, é um dos factores que fomentam maiores desigualdades sociais e territoriais com consequências na sua coesão e desenvolvimento. A concentração territorial provoca uma "espiral de declínio» que potencia a sua decadência e a das escolas que as servem, tal como as vizinhanças mais prósperas beneficiam de bons resultados escolares.

A diversidade tem sido uma riqueza proporcionada pelas cidades. A diversidade de usos, gerações, etnias, culturas e rendimentos no território (na cidade ou na metrópole), como contraponto à segregação (social, económica, cultural ou funcional) será uma resposta para assegurar um dinamismo urbano positivo e equitativo, essencial para garantir a igualdade de oportunidades a todos os seus habitantes com reflexos directos na eficiência e eficácia escolar. Tal pode ser alcançado através:

- da oferta de habitaçáo a custos controlados em novos empreendimentos. O modo de gestão da oferta e da conservação do parque habitacional repercute-se na diversidade da cidade e, por consequência, na escola. Por isso as «políticas de habitação são políticas de educação» (Rusk 2003, p.4).

- da criação de emprego junto de bairros com problemas sociais, que favorece a diversidade, atraindo outras populaçóes e abrindo novas oportunidades aos seus residentes. A associação e articulação de algumas actividades aos equipamentos escolares podem gerar sinergias positivas.

- da acessibilidade e a mobilidade, que permitem um acesso mais equitativo a tudo o que a cidade oferece. Os equipamentos, o emprego e os espaços de consumo e lazer são 
fundamentais na integração das comunidades mais desprotegidas. A permeabilidade/ /conectividade das zonas marginalizadas também é relevante para a interacção com outras comunidades.

- do nível institucional, forma insubstituível de integração. Em torno das instituições públicas e da sociedade civil congregam-se comunidades, o que contribui para coesão territorial. Estas devem, por isso, ter uma representação equitativa no território. A escola, que historicamente desempenhou esse papel, terá de partilhá-lo com outras redes institucionais emergentes, mas deverá ser o seu centro durante a idade da aprendizagem.

Para operacionalizar o Urbanismo Escolar propomos uma abordagem metodológica assente nas seguintes ideias força: territorialização - o território como centro do planeamento, da gestão e administração; integração - dos instrumentos e políticas urbanas e educativas, que permita agir conjuntamente sobre os factores que interferem na capacitação dos territórios; articulação - entre os níveis de planeamento e gestão, tendo cada escala de encontrar respostas adequadas para os problemas encontrados; participação - dos cidadãos e dos agentes na construção das soluçóes, da génese à sua execução e avaliação; flexibilização - nos métodos e processos de planeamento e gestáo, assim como às diferentes escalas e tempos, adaptando-os às condiçóes e culturas locais, mas respeitando os objectivos a atingir; inovação - experimentação nos processos e ferramentas tecnológicas, tornando-o aberto à comunidade; avaliação - como parte do processo, pois este é dinâmico e carece verificação do cumprimento dos objectivos.

$\mathrm{O}$ estudo de cada realidade permite perceber as dinâmicas territoriais (incluindo as dimensóes sociais, económicas, educacionais) e estabelecer as unidades operativas de planeamento e gestão que deverão convergir com os «territórios educativos», fortalecendo a integração da carta educativa nos instrumentos de planeamento territorial. Os limites das unidades devem partir de uma decisão técnica/política, mas ser sujeitos à participaçáo pública e a sua reconfiguração ser flexível para se adaptar às tendências de evolução territorial. As Cartas Educativas passariam a estar articuladas com os instrumentos de planeamento territorial, através da criação das Unidades Operativas de Planeamento e Gestão, urbanas e educativas. Estas teriam uma visão mais alargada, que não perdesse a noção do particular e de conjunto, onde, a coesão territorial, e a equidade social (do bairro, cidade ou regiáo) estivessem garantidas. Mas como? De seguida daremos algumas indicaçóes.

Escala local. As unidades ao nível do bairro ou aglomerado estariam abertas à possibilidade de integração dos projectos educativos dos agrupamentos com o planeamento urbano, nomeadamente: na definição das acessibilidades (diversificadas e potenciadoras de mobilidades não poluentes), no ambiente (criaçáo de hortas pedagógicas, promoção de hábitos "verdes"), na saúde (incorporando os cuidados primários de saúde e promovendo hábitos saudáveis), desporto (partilha de espaços desportivos e do desporto para todos), espaços públicos (multifuncionais). E na gestão dos recursos físicos (articulação de estacionamento, espaços culturais e desportivos, bibliotecas) e humanos (mobilidade e partilha de recursos) assim como em alguns serviços (alimentares, administrativos, formativos) e logística associados. A boa localização e inserção urbana, a esta escala, são determinantes para uma interacção virtuosa entre tecido urbano e escola. A arquitectura do edifício e o desenho urbano devem assegurar que a escola se constitua numa centralidade física e simbólica da comunidade e as acessibilidades às escolas estar integradas nos corredores verdes e/ou percursos pedonais na malha urbana. 
Escala municipal. A rede de equipamentos educativos estaria em articulação com o modelo de organização territorial e a estratégia de desenvolvimento local subjacente. As opçóes de concentração e desconcentração dos equipamentos deveriam fazer a ponderação entre os «interesses» territoriais e sectoriais, considerando diferentes realidades, mas sempre comprometer o princípio da equidade. A articulação da escola com equipamentos complementares ou espaços comerciais poderia ser benéfica para todos, partilhando valências e permitindo um melhor uso urbano (menos deslocaçóes, maior rentabilizaçáo do tempo das famílias). Esta escala deveria integrar a definição da rede de transportes (transporte escolar dedicado só quando justificado) e disponibilizar meios saudáveis e não poluentes com dimensão e horários adequados às necessidades da escola e das famílias.

Escala inter-municipal. A dimensão concelhia não resolve muitos dos problemas territoriais e da rede escolar. O enquadramento inter-municipal, até agora subestimado, ganha relevância (a extensão da escolaridade obrigatória ao secundário exigirá a reconfiguração das redes num âmbito mais alargado).

Com a metodologia proposta, o Urbanismo Escolar procura uma permanente aproximação entre a política educativa e as políticas urbanística e de ordenamento do território, para garantir a coesão e a equidade, social e territorial, essenciais à promoção do desenvolvimento desejado.

\section{REFERÊNCIAS BIBLIOGRÁFICAS}

Alves, N. 2009, 'Novos Factos Sobre a Pobreza em Portugal', Boletim Económico do Banco de Portugal Primavera, Vol.15, n. ${ }^{\circ} 1, \mathrm{pp} .125-154$.

Amaro, R. R. 2006, 'Desenvolvimento um conceito ultrapassado ou em renovação? - da teoria à prática e da prática à teoria', in Ensaios de Homenagem a António Simóes Lopes, ISEG/UTL, Lisboa.

Carneiro, P. 2008, 'Equality of Opportunity and Educational Achievement in Portugal?' Portuguese Economic Journal, n. o 7 , pp.17-41.

Centro de Estudos de Planeamento 1978, Equipamentos Colectivos, CEP, Volume I, Lisboa.

DGOTDU 2002, Normas para a Programação e Caracterização de Equipamentos Colectivos - Equipamentos de Educação, "Ministério da Educação", Colecção informação 6, Lisboa.

Ellen, I. G., Turner, M. A. 1997, 'Does Neighborhood Matter? Assessing Recent Evidence', Housing Policy Debate, Volume 8, Issue 4, Virginia (USA), pp. 833-866.

Gaspar, J. e al. 2000, “As Dinâmicas de Contexto - Desenvolvimento Sustentável: As pessoas o Espaço, o Ambiente - População e Sistema Educativo”. in Carneiro, R. (Org.), O Futuro da Educação em Portugal Tendências e Oportunidades - um estudo de reflexão prospectiva. Tomo II, Dinâmicas de Contexto, DAPP, Lisboa, pp. 227-269.

Gaspar, J. 2006, Planeamento e Ordenamento do Território, in Geografia de Portugal, volume 4, Circulo de Leitores, Lisboa.

Kaztman, R. \& Rematoso, A. 2005, Segregación Residencial En Montevideo: Desafios para la equidad educativa, Communicated in Seminar Urban Governance and Intra Urban Population Differentials in Latin American Metropolitan Areas. University of Texas, Austin, 17 al 19 de Noviembre.

Lima, J. Á. 2008, Em Busca da Boa Escola, Fundaçáo Manuel Leão, Vila Nova de Gaia.

Lubell, J. Brennan, M. 2007, Framing the Issues - The Positive Impacts of Affordable Housing on Education, Center for Housing Policy.

Mackoy, D. L., Vicent, J.M. 2008, 'Housing and Education: The Inextricable Link'. In Segregation: The Rising Costs for America. (Edited by J. Carr and N. Kutty), Routledge New York.

Marques, T. S. 2004, Portugal na Transição do Século: Retratos e Dinâmicas Territoriais, Edições Afrontamento, Santa Maria da Feira

ME, 2000a, Critérios de Reordenamento da Rede Educativa, Europress Lda, Lisboa.

ME, 2000b, Manual para a Elaboração da Carta Educativa, Europress Lda, Lisboa.

OCDE, 2008, Growing Unequal? Income Distribution and Poverty in OECD Countries, Paris. 
Pereira, M. \& Pisco, P. 2010, Coesão Territorial e Equidade Social: importância estratégica dos equipamentos colectivos, Actas do Encontro Anual: Os dez anos da Lei de Bases da Politica de Ordenamento do Território e de Urbanismo (12 Dezembro 2008), DGOTDU, Lisboa, pp.209-222.

Perry, L. B. 2007, School Composition and Student Outcomes: A Review of Emerging Areas of Research, Annual Conference of the Australian Association for Research in Education, Fremantle.

Pisco, P 2005 A Escola como Factor Organizador do Espaço Urbano: O Contexto das Capitais de Distrito, IST, UTL (dissertação de Mestrado em Urbanística e Gestão do Território), Lisboa.

Pisco, P. 2009, Desenvolvimento, Coesão e Equidade na Educaçâo: Será a Escola Suficiente? Bragança: Actas do X Congresso da Sociedade Portuguesa de Ciências da Educação, Bragança.

Schneider, M. 2002, Do School Facilities Affect Academic Outcomes? National Clearinghouse for Educational Facilities, Washington D.C.

Ribeiro, L. C. Q. 2008, 'Sucesso/Insucesso escolar e Segregação residencial: A Divisão Favela X Bairro e Defasagem Idade Série no Rio de Janeiro', in Cabral, M. V., Sucesso e Insucesso: Escola, Economia e Sociedade, FCG, Lisboa.

Rusk, D. 2003, Housing Policy Is School Policy. Remarks to the $44^{\text {th }}$ Annual Meeting of a Baltimore Neighborhoods, Inc.

Fundo de População das Nações Unidas 2007, Situação da População Mundial 2007, UNFPA, Nova York. 